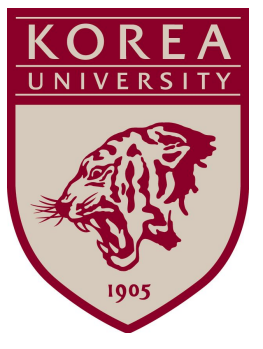

Discussion Paper Series

No. 1003

Jan 2010

\title{
Impact of University Scientists on Innovations in Nanotechnology
}

Jinyoung Kim, Sangjoon John Lee, and Gerald Marschke

The Institute of Economic Research - Korea University

Anam-dong, Sungbuk-ku, Seoul, 136-701, South Korea, Tel: (82-2) 3290-1632, Fax: (82-2) 928-4948

Copyright (C) 2010 IER. 


\title{
Impact of University Scientists on Innovations in Nanotechnology ${ }^{*}$
}

\author{
Jinyoung $\mathrm{Kim}^{\dagger}$, Sangjoon John Lee ${ }^{\dagger \dagger}$, and Gerald Marschke ${ }^{\dagger \dagger}$ \\ ${ }^{\dagger}$ Korea University \\ ${ }^{\dagger \dagger}$ Alfred University \\ ${ }^{\dagger \dagger}$ University at Albany and NBER
}

April, 2008

\begin{abstract}
Using U.S. patent records in nanotechnology, we study the impact of university research on industry innovations with the premise that knowledge is diffused from universities to industry via personnel with university research experience. Appearing on a patent assigned to a university is evidence that an inventor has been exposed to university research, either directly as a university researcher or through some form of collaboration with university researchers. Over the period 1985-97, we find a steady increase in industry's employment of inventors with university research experience. In the 1990s we find the productivity (in terms of patenting rates and patent quality) of inventors with university backgrounds begins to exceed the productivity of the inventors without such experience. We also find that the share of industry patents in nanotechnology that cite university-assigned patents almost doubles during the period and inventors with university experience cite mostly university patents not invented by them, implying that they are instrumental in transferring general knowledge created throughout the university community.
\end{abstract}

JEL Classification: J62, O31, O33

Key words: Nanotechnology, Patents; Innovation; Knowledge spillovers; University research

\footnotetext{
*All errors are exclusively the responsibility of the authors. Comments welcome at Jinyoung Kim, Department of Economics, Korea University, 5-1 Anam-Dong, Sungbook-Ku, Seoul, Korea, jinykim@korea.ac.kr; and Gerald Marschke, Department of Economics, SUNY Albany, BA-110, Albany, NY 12222, marschke@albany.edu.
} 


\section{Introduction}

Nanotechnology is one of the fastest-advancing fields in science and technology and is anticipated to have great contributions in many large and economically important industries such as information technology and medicine, and consequently, in technological progress and economic growth. For this reason, many studies in economics have been recently initiated to understand how nanotechnology is diffused and transmitted through the economy. In this paper we study one particular channel through which nanotechnology is transmitted: from university to industry.

The outcomes of university research disseminate along a number of pathways: through scholarly publications and the material published in universities' patent applications, at conferences where scholarly work is presented and where industry and academic research personnel commingle, and via informal social networks. ${ }^{1}$ But firms also learn about university research after employing or collaborating with researchers who work or have worked in university laboratories. In fact, social scientists who study innovation suspect that certain kinds of important knowledge become available to a firm only with sustained, close interaction with researchers who possess this knowledge as through an employment or collaborative research arrangement.

We propose to examine the role of research personnel as a pathway for the diffusion of ideas from university to industry, especially nanotechnology industry, utilizing information contained in patent records. The inventors behind the patented invention are listed on each patent, as are the firms, government organizations, and universities to which the patents are assigned. Using a procedure proposed in Kim, Lee,

\footnotetext{
${ }^{1}$ See Cohen, Nelson and Walsh (2002) on the various means by which innovating firms access know-how developed externally. See Agrawal, Cockburn, and McHale (2003) for evidence of the importance of social networks in promoting diffusion.
} 
and Marschke (2008), we match names on patents to construct a panel data set of inventors that contains the patents in each year of the inventors' careers. We are thus able to identify for each inventor when and how often he or she is innovating for university and industry assignees. For each patent assigned to industry we can tell whether its inventors had previously appeared as an inventor on a patent assigned to a university. Appearing on a patent assigned to a university is evidence that the inventor had exposure to university research, either directly as a university researcher or through some form of collaboration with university researchers. In this paper, we investigate how the influence of university research on nanotechnology innovations has evolved over the last few decades, through inventors’ university inventing and research experience. In addition, we probe how productive inventors with university experience are in patenting, relative to those without and how their productivity has evolved over time.

We also use patent citations to infer the extent of industry access to universityproduced knowledge and how that access has changed. Patent applicants are legally obligated to disclose any knowledge they have of previous relevant inventions. The patent examiner may add to the application relevant citations omitted by the applicant. Thus, through the patent citations each patent documents the "prior art" upon which the new innovation builds, and because we know each cited patent's assignee type, we know whether the prior art originated in university laboratories. We also investigate how frequently industry patents in nanotechnology cite university patents that name inventors who are also named in those industry patents. This investigation can tell us how the presence of university-experienced inventors is instrumental in transmitting more general knowledge created throughout the university community. 
Our main findings are the following. Over the period 1985-1997, we find that (1) the share of nanotechnology patents assigned to universities increased substantially, (2) the nanotechnology industry increased its employment of inventors with experience on university research projects, (3) those inventors with university research experience showed a similar productivity in patenting as those without before the early 1990's, but a higher productivity since then, (4) the share of industry patents in nanotechnology that cite university-assigned patents almost doubled, and (5) the typical firm's patents that cite university-assigned patents cite university patents that have no inventors in common with the firm, which implies the presence of university-experienced inventors is instrumental in transmitting research output from the university sector in general, rather than their own research output.

The paper is organized as follows. The next section summarizes the literature on the various mechanisms for university technology transfer to industry, technology spillovers, scientist collaboration and mobility, and the use of patent citations to trace technological diffusion. Section III describes our data, focusing on the construction of the inventor panel. Section IV describes levels and trends in university involvement in nanotechnology industry. Section V offers concluding remarks.

\section{Literature Review}

Two decades of empirical work suggests important and pervasive effects of university research on industry R\&D and innovation (e.g., Jaffe, 1989; Adams, 1990; Mansfield, 1991, 1998; Nelson and Rosenberg, 1993; Cohen, Nelson, and Walsh, 2002). ${ }^{2}$ Mansfield (1991) roughly estimates the annual social rate of return to university research

\footnotetext{
${ }^{2}$ See Cohen, Florida, Randazzese, and Walsh (1998) for a survey of this evidence.
} 
over the years 1975 through 1978 to be 28 percent. While the diffusion of technology from the academic to the industrial sector is thought to be important, little is known about the transmittal mechanisms. Scholars writing in both the economics and sociology of innovation literatures argue that new technologies are frequently difficult to transmit to the uninitiated via spoken or written communication (see Polanyi, 1958, 1966 for early discussions of the 'tacitness' of knowledge). Often the most efficient means of transmission across organizational boundaries for tacit knowledge is via person-to-person contact involving a transfer or exchange of personnel. Recent findings that technological diffusion appears to be geographically limited (e.g., Jaffe, 1989; Jaffe, Trajtenberg, and Henderson, 1993; Zucker, Darby, and Brewer, 1998; and Mowery and Ziedonis, 2001) are often interpreted as evidence of the tacitness of knowledge.

More direct evidence exists that person-to-person interaction is important for the diffusion of technology. Cohen, Nelson, and Walsh (2002) surveyed R\&D managers on the means by which they gather and assimilate new technologies. They find that firms access externally-located technology partly through the hiring of and collaboration with researchers from the outside. Moreover, they find that hiring/collaboration with outside scientists is complementary to other means of accessing externally produced knowledge, such as through informal communications with outsiders and more formal (such as consulting) relationships with outsiders. Almeida and Kogut (1999) find that firms are more likely to cite patents of other firms in their region if inventor mobility rates are high, offering circumstantial evidence that ideas in the semiconductor industry are spread by the movement of key engineers among firms, especially within a geographical area. ${ }^{3}$

\footnotetext{
${ }^{3}$ See also the (indirect) evidence of a link between scientific mobility and technological diffusion in Kim and Marschke (2005) and Moen (2005).
} 
Zucker, Darby, and Armstrong (2001) find evidence of a pay-off to firms that seek interactions with outside researchers. They find a positive impact on patent productivity for biotech firms that collaborate with university researchers on research and scholarly publications.

We therefore anticipate that the evidence, while presently incomplete, will eventually show that the migration of university-experienced scientific personnel to industry is an important means of technology transfer and that it complements other mechanisms. Assuming this to be the case, we use measures of the industrial employment of university-experienced researchers to track the extent to which industry is accessing university technologies.

We also use patent citations to track the diffusion of university innovations. Some scholars have used citations to university and industrial patents to compare the relative importance of innovations arising from these sectors and to examine how changes in patent law have influenced the importance of university patents (Henderson, Jaffe, and Trajtenberg, 1998; Sampat, Mowery, and Ziedonis, 2003). Others have looked at the determinants of a university patent's likelihood of being cited (Jaffe and Trajtenberg, 2002) and the trend in citations of industry patents to university research publications (Narin et al., 1997). To our knowledge, ours is the first study that examines the extent to which industrial patents cite university patents.

\section{Data Description}

The data used in this paper are a part of the inventor-firm panel database that we created (see Kim, Lee and Marschke, 2008, for the detailed description of the 
construction procedure). The data for this paper are derived from three sources: (1) Patent Bibliographic data (Patents BIB) released by the U.S. Patent and Trademark Office (USPTO) that contain bibliographic information for U.S. utility patents issued from 1975 to 2002; (2) the NBER Patent-Citations data collected by Hall, Jaffe and Trajtenberg (2001) which contain all citations made by patents granted in 1975-1999; and (3) the Nanobank database collected by Zucker and Darby (2007) that identifies patents in nanotechnology. To create our data from these sources, we match inventor names in the Patents BIB database, and add information from the citation data. We then select only those patents in nanotechnology based on the Nanobank database. The following describes the name matching method.

\section{Inventor name matching}

Since the 1960's the information contained in patent data have been extensively used to investigate various issues such as technology spillovers and R\&D productivity at the industry or firm level. The information on inventors contained in patent data, however, has not been fully utilized possibly because of the difficulty in identifying whether two names in the inventor name field from two patents belong to the same inventor. Using inventor's name (last, first, and middle), address, city, state, zip (often missing), and country at the time of grant of the patent, we attempt in this paper to match inventor names and produce each inventor’s life-cycle productivity in patenting.

To start, we treat each entry that appears in the inventor name field of every patent in the Patents BIB data as a unique inventor. Given $\mathrm{N}$ number of names in this name pool, we pair each name with all other names, which generates $\mathrm{N}(\mathrm{N}-1) / 2$ number of 
unique pairs. The 5.1 million names in the Patents BIB data (2.05 inventors per patent) thus produce 13 trillion unique pairs. For each pair, we consider the two names as belonging to the same inventor if the SOUNDEX codes of their last names and their full first names are the same, and at least one of the following three conditions is met: (1) the full addresses for the pair of names are the same; (2) one name from the pair is an inventor of a patent that is cited by another patent whose inventors include the other name from the pair; or (3) the two names from the pair share the same co-inventor. In implementing the second and third conditions, we make comparisons based on whether the first and last names are spelled identically. After our name matching procedure is completed, we go back and check that these conditions are still valid based on the inventor identifier constructed by the matching procedure. If not, we repeat the name matching process to create a new inventor identifier.

SOUNDEX is a coded index for last names based on the way a last name sounds in English rather than the way it is spelled. Last names that sound the same, but are spelled differently, like SMITH and SMYTH, have the same SOUNDEX code. We use the SOUNDEX coding method to expand the list of similar last names to overcome the potential for misspellings and inconsistent foreign name translations to English; misspellings are common in the USPTO data as are names of non-Western European origin (see Appendix A for the detailed SOUNDEX coding method).

We also consider a pair of names as a match if two have the same full last and first names as spelled in the Patent BIB data, and at least one of the following conditions is met: (1) the two have the same zip code; (2) they have the same full middle name; or (3) they reside in the same MSA area. Given all pairs of names that are considered as 
matches by the preceding procedures, we impose an additional matching criterion that a pair of names is not treated as a match if their middle name initials are different. We then impose transitivity in the following sense: If name A is matched to name B and name B is matched to name $\mathrm{C}$, name $\mathrm{A}$ is then matched to name $\mathrm{C}$. We iterate this process until all possible transitivity matches are completed. At this point we assign the same inventor ID number for all the names matched. Using this method, we identified 1.72 million unique inventors (34\%) out of 5.1 million names in the entire patent data.

After name matching, we add information on all citations from the NBER PatentCitations data collected by Hall, Jaffe and Trajtenberg (2001) where each citing patent that was granted between 1975 and 1999 is matched to all patents cited by the patent. As the final step, we select only those patents in nanotechnology that are identified in the Nanobank database.

\section{Results}

\section{Trends in Nanotechnology Patents}

Table 1 reports the annual number of patent grants in nanotechnology by application year. The table shows a rapid increase in the number of patent grants between 1975 and 1997, with the average annual growth rate at 10.78 percent. This growth rate is significantly higher than the growth rate of the total number of U.S. patent grants (about 4 percent annually during this period), which suggests that nanotechnology is making a fast progress.

The number of patent grants in nanotechnology assigned to universities is shown in Table 1 to grow even faster at 18.35 percent annually. The share of university- 
assigned patents in nanotechnology has thus increased between 1975 and 1997, from 2.2 to 7.2 percent (see Figure 1). ${ }^{4}$ During this period, this share among all U.S. patents increased from 0.16 percent in 1975 to 1.97 percent in 1997, which indicates that the involvement of university research in nanotechnology has been more significant.

Table 1 shows a steady increase in the number of patent grants in nanotechnology between 1975 and 1995, from 2004 to 16522 patents. The number then dropped from 16522 in 1995 to 14555 in 1996 before recovering in 1997. This precipitous rise and fall of the number of patents is puzzling-we observe this phenomenon in the other figures discussed below_-but may be related to a change in patent law in 1995. Until 1995, successful patent applicants received a 17 year monopoly on the use of their invention from the date the patent was granted. For applications filed after June 8, 1995, patented applicants received a 20 year monopoly commencing from the date of the patent application. This new law may have changed the duration of the monopoly for many patent holders, affording longer monopoly periods for patents that are approved quickly, and shorter periods for patents whose review procedure is delayed, as by an appeal or an interference proceeding. In addition, the new law provided that patents applied for prior to June 8, 1995 and issuing on or after June 8 would expire either 17 years from issuance, or 20 years from the date of original application, whichever generated the longer monopoly period (Radack, 1995; Elman, Wilf, and Fried, 1995). These relatively generous terms may have for the short transitional period made some marginal innovations worth the opportunity cost of patenting. The distinctive blip of the patent number in 1995 may reflect a rush to file patents before the June 7 expiration date to take

\footnotetext{
${ }^{4}$ Our university assignees include domestic universities, hospitals, research laboratories (non-government), and non-profit organizations in the U.S.
} 
advantage of the opportunity to lock in an extended monopoly period. Moreover, because basic research has a longer shelf life, universities with inventions constituting basic research may have been especially keen to obtain the longer monopoly period. Thus it seems to us natural to see an increase in the share of university-assigned patents in Figure 1 during the transition period.

\section{Inventors with University Experience}

Figure 2A shows the annual percentage of industry-assigned patents in nanotechnology that list at least one inventor who had previously been named an inventor on a university-assigned patent applied for sometime in the previous ten years. Because our data included patents granted in 1975 and later, we imposed a cut-off for the patents used to define whether an inventor was university-experienced at the time of the industry patent's application. We chose to consider only those university-assigned patents on which the inventor appeared in the ten years prior to the date of the industry patent's application because ten years still leaves us a long period over which to conduct our analysis and because skills or knowledge acquired in a university setting far in the past may not be very valuable. Figure 2A shows this measure for all patents granted to U.S. industry assignees in nanotechnology by application year for the years 1985 through 1997.

Figure 2A shows a steady increase in the share of patents with inventors who had university experience between 1985 and 1995, from 2.4 to 6.3 percent. This share then drops to 5.2 percent in 1996 before recovering to 5.7 in 1997 . This temporary surge may also be due to the change in patent law in 1995, as explained in the previous section. During the same period, the share of patents with university-experienced inventors 
among all U.S. patents rose as well at a similar pace as that in nanotechnology, but the average share in nanotechnology (3.77\%) was significantly higher than for all U.S. patents (1.51\%). This finding, together with the finding in the previous section, indicates that university research is more closely involved in nanotechnology. Kim, Lee and Marschke (??) report that for the period 1989 through 1997 patents in the pharmaceutical industry were more likely and those in the semiconductor industry were less likely to include an inventor who had university patent experience than in nanotechnology: the share was about 6.6 percent and 1.9 percent in pharmaceutical and semiconductor industry, respectively, while it was 4.5 percent in nanotechnology.

One concern is that firms may have been interacting with university-experienced inventors in earlier years at the same rate as in later years but because universities infrequently patented before the 1980s we do not detect it. Figure 2B reports the fraction of inventors with university patenting experience in the last 10 years who appear on industry patents in nanotechnology by application year; this measure does not suffer from the aforementioned problem. Figure 2B shows that between 1985 and 1997 the alternative measure exhibits similar dynamics.

It appears then that industry has increasingly found university-experienced inventors useful. With Figures 3 and 4 we examine whether there are productivity differences between university-experienced and non-university-experienced inventors. Figure 3 tracks how the quality of inventors' output changes by inventor type. There is evidence that citations received reflect the economic value of the patent (Trajtenberg, 1990). Figure 3 shows the citations received in the 5-year period following application per patent by inventor type over time. This figure covers only years of application 
through 1992 because the NBER citation data contain citations made by patents granted in years up to 1999 and we take into account the 5-year period of citation and a 2-year gap between application and granting dates. Between 1985 and 1992, the citations per patent rose for both classes of inventors. The figure shows, however, that while the citation rates were very similar in 1985, by 1992 patents with university-experienced inventors on them received about one-half of a citation more than patents without university-experienced inventors.

Are those inventors who had university patent experience in nanotechnology more prolific in terms of patenting than those without? Figure 4 shows the trends in patent productivity for two groups of inventors who had at least one nanotechnology patent in a given year as well as at least one patent in the previous 10 years. The first group includes those who had previously been named an inventor on a university-assigned patent applied for sometime in the previous ten years, and the second group includes those without university patent experience. In this figure we include only inventors who had at least one patent in the previous 10 years because those inventors in the first group can only be identified when they have at least one patent. Figure 4 shows that the productivity in patenting diverged somewhat between the two groups of inventors after the 1990's, indicating that nanotechnology is attracting more productive researchers out of university research.

\section{Citation to University Patents}

Citations to patents assigned to universities may reflect the extent of industry access to university-produced knowledge. Figure 5A shows the annual percentage of 
industry-assigned patents that cite as prior art at least one university patent applied for within the previous ten years. This figure shows a steady increase in this percentage between 1985 and 1995, from 8.9 percent to 21.6 percent, followed by a decline through the end of the period to 16.4 percent, which implies that there may have been a steady increase in knowledge flows from universities to industry in nanotechnology. During the same period, the annual average percentage also rose steadily for all industries at the similar growth rate as in nanotechnology, but the magnitude of the knowledge flow seems to be significantly bigger in nanotechnology than in all industries in general: the average percentage for nanotechnology was 13.9 percent while it was 5.2 percent for all industries.

Firms may have been influenced by university research in earlier years, but because university research was patented at lower rates industry access was not as apparent. Thus we create a measure of the likelihood that a university patent is cited by industry. Figure 5B shows the percentage of 10-year old and younger university patents that are cited, by application year. Like the percentage in Figure 5A, this new measure generally increases from 1985 through 1995, after which it falls precipitously.

University-experienced researchers who move from universities to industry can transfer specific knowledge or human capital that they have created themselves before they move. It is also possible that moving researchers are instrumental in transferring more general knowledge accumulated through universities. In order to quantify these two types of knowledge transfer, Figure 6 reports the annual percentage of industry patents whose inventors appear as inventors in at least one university patent in the previous 10 years that is cited by the industry patents. This percentage therefore 
measures how frequently industry inventors self cite their university patents. Over the period 1985-97, the self-citation ratio was quite stable at about 5 percent. This finding implies that the direct transfer of specific knowledge created by university-experienced inventors is relatively small. On the other hand, they tend to induce the transfer of knowledge that is more generally accumulated through the university system.

\section{Conclusion}

Our findings suggest that university research has increasingly influenced technological innovations in nanotechnology in various aspects. More innovations in nanotechnology are originated from university research in recent years as evidenced by increasing share of university-assigned patents. Industry's use of inventors with past experience conducting university research has increased in nanotechnology and nanotechnology industry is attracting university-experienced inventors, whose productivity in the 1990s began to exceed the productivity of inventors without that experience, both in terms of the number patents produced and their quality. This may mean that innovating firms in nanotechnology have increased their access to universityproduced knowledge through the knowledge imbedded in inventors' human capital. That industry is making greater use of university-produced knowledge is also reflected in the citation data. We observe an increase in citing university patents in nanotechnology. We also find evidence that inventors moving from universities to industry are instrumental in transferring not just inventor-specific knowledge but also more general knowledge created by the university research community. 
Needless to say, we recognize a number of shortcomings in our analysis that we plan to address in future work. For example, our name matching procedure undoubtedly is subject to error, sometimes treating different inventors as a single inventor (overmatching), and other times treating the same inventor as different inventors (undermatching). These matching errors are likely more important in the analysis of levels of involvement with university research, as opposed to the analysis of trends. Nonetheless future work will attempt alternative matching rules for the sensitivity of our findings. So far we have found that undermatching error appears to be due primarily to the importance that the algorithm places on the inventor's middle name for matching and the inconsistency with which an inventor's middle name is represented from one patent to the next patent. We are currently testing an improved version of the matching algorithm that allows for more variation in the way the middle name appears. Preliminary testing suggests that the new algorithm significantly reduces undermatching error at little cost in increased overmatching error.

An interesting question which is not investigated in this paper is how the use of university research affects the productivity of $R \& D$ in firms. Another interesting question is how start-up firms utilize university research. In future work, we plan to explore theses issues. 


\section{Appendix A. SOUNDEX coding system}

A SOUNDEX code for a surname is an upper case letter followed by 6 digits. For example the SOUNDEX code for Kim is K500000, while that for Marschke is M620000. The first letter is always the first letter of the surname. The rules for generating a SOUNDEX code are:

1. Take the first letter of the surname and capitalize it.

2. Go through each of the following letters giving them numerical values from 1 to 6 if they are found in the Scoring Letter table (1 for B, F, P, V; 2 for C, G, J, K, Q, S, X, Z; 3 for D, T; 4 for L; 5 for M, N; 6 for R; 0 for Vowels, punctuation, H, W, Y).

3. Ignore any letter if it is not a scoring character. This means that all vowels as well as the letters $\mathrm{h}, \mathrm{y}$ and $\mathrm{w}$ are ignored.

4. If the value of a scoring character is the same as the previous letter then ignore it. Thus if two 't's come together in the middle of a name they are treated exactly the same as a single ' $\mathrm{t}$ ' or a single ' $\mathrm{d}$ '. If they are separated by another non-scoring character then the same score can follow in the final code. The name PETTIT is P330000. The second ' $\mathrm{T}$ ' is ignored but the third one is not since a nonscoring ' $\mathrm{I}$ ' intervenes.

5. Add the number onto the end of the SOUNDEX code if it is not to be ignored.

6. Keep working through the name until you have created a code of 6 characters maximum.

7. If you come to the end of the name before you reach 6 characters, pad out the end of the code with zeros.

8. Optionally you can ignore a possessive prefix such as 'Von' or 'Des'.

See "Using the Census SOUNDEX," General Information Leaflet 55 (Washington, DC: National Archives and Records Administration, 1995) for the detailed method. 


\section{References}

Adams, James D. 1990. "Fundamental Stocks of Knowledge and Productivity Growth." The Journal of Political Economy, 98(4), pp. 673-702.

Agrawal, Ajay K., Cockburn, Iain M., and McHale John 2003 "Gone but Not Forgotten: Labor Flows, Knowledge Spillovers, and Enduring Social Capital,” NBER Working Paper no. 9950

Cockburn, Iain M. and Henderson, Rebecca M. 1998. "Absorptive Capacity, Coauthoring Behavior, and the Organization of Research in Drug Discovery." The Journal of Industrial Economics, 46(2), pp. 157-182.

Cohen, Wesley M., Nelson, Richard R., and Walsh, John P. 2000. "Protecting Their Intellectual Assets: Appropriability Conditions and Why U.S. Manufacturing Firms Patent (or Not),” NBER Working Paper no. 7552

Cohen, Wesley M., Nelson, Richard R., Walsh, John P. 2002. "Links and Impacts: The Influence of Public Research on Industrial R\&D.” Management Science, 48(1), pp. 1-23

Elman, Wilf, and Fried. 1995. "The Impact of GATT on Patent Tactics," 'Electric Law Library, http://www.lectlaw.com/files/inp03.htm

Goldin, Claudia and Katz, Lawrence, 1998. "The Origins of Technology-Skill Complementarity,” Quarterly Journal of Economics, 113, pp. 693-732.

Griliches, Zvi, 1969. "Capital-Skill Complementarity," Review of Economics and Statistics, 51, pp. 465-468.

Hall, B., Jaffe, A. and Trajtenberg, M. "Market Value and Patent Citations: A First Look.” NBER Working Paper No. 7741, 2000.

Hicks, Diana, Breitzman, Tony, Olivastro, Dominic and Hamilton, Kimberly, "The Changing Composition of Innovative Activity in the US--A Portrait Based on Patent Analysis.” Research Policy, 30 (4), 2001, p 681-703.

Jaffe, Adam B. 1989. "Real Effects of Academic Research.” The American Economic Review, 79(5), pp. 957-970.

Jaffe, Adam B. and Trajtenberg, Manuel. 1992. "Flows of Knowledge from Universities and Federal Laboratories: Modeling the Flow of Patent Citations over Time," in Patents, Citations, and Innovations: A Window on the Knowledge Economy, Jaffe, Adam B. and Trajtenberg, Manuel, eds. Cambridge, Massachusetts: The MIT Press. 
Kim, Jinyoung and Marschke, Gerald, 2005, "Labor Mobility of Scientists, Technological Diffusion, and the Firm's Patenting Decision," The Rand Journal of Economics, forthcoming, 2005.

Mansfield, E., 1991. “Academic research and industrial innovation.” Research Policy, 20(1), pp. 1-12.

Mansfield, E., 1998. "Academic research and industrial innovation: An update of empirical findings.” Research Policy, 26 (7-8), pp. 773-776.

Moen, Jarle. (2005) "Is Mobility of Technical Personnel a Source of R\&D Spillovers?," Journal of Labor Economics, 23(1), pp. 81-114.

Mowery, David C. and Ziedonis, Arvids Alexander, "The Geographic Reach of Market and Non-Market Channels of Technology Transfer: Comparing Citations and Licenses of University Patents" (October 2001). NBER Working Paper No. W8568.

Narin, Francis, Hamilton, Kimberly S. and Olivastro, Dominic, 1997. "The increasing linkage between U.S. technology and public science,” Research Policy, 26, pp. 317-330.

Nelson, Richard R, Nathan Rosenberg (1993), "Technical Innovation and National Systems”, in R. R. Nelson ed., National Systems of Innovation. A Comparative Analysis. Oxford University Press: Oxford, pp. 3-21.

Parr, Russell L. and Sullivan, Patrick H. Technology Licensing: Corporate Strategies for Maximizing Value, John Wiley \& Sons, Inc, New York, NY, 1996.

Polanyi, Michael. Personal Knowledge: Towards a Post-Critical Philosophy (University of Chicago Press, Chicago, 1958)

Polanyi, Michael. The Tacit Dimension (Doubleday, Garden City, NY, 1966)

Radack, David V. 1995. “GATT Brings Major Changes in U.S. Patent Law,” JOM, 47(5), p. 79

Sampat, Bhaven N., Mowery, David C., and Ziedonis, Arvid A. 2003 "Changes in University Patent Quality after the Bayh-Dole Act: A Re-Examination,” Working paper, Georgia Institute of Technology.

Trajtenberg, Manuel, "The Names Game: Using Inventors Patent Data in Economic Research,” Working paper, 2004.

Trajtenberg, Manuel. "A Penny for Your Quotes: Patent Citations and the Value of Innovations.” The Rand Journal of Economics. Vol. 21, No. 1, pp. 172-87, Spring 1990. 
Zucker, Lynne G.; Darby, Michael R.; Armstrong, Jeff S. "Commercializing Knowledge: University Science, Knowledge Capture, and Firm Performance in Biotechnology" NBER Working Paper No. 8499, October 2001

Zucker, Lynne G.; Darby, Michael R.; and Brewer Marilynn B. "Intellectual Human Capital and the Birth of U.S. Biotechnology Enterprises" The American Economic Review, Vol. 88, No. 1. (Mar., 1998), pp. 290-306. 
Figure 1 Share of University-Assigned Patents in Nanotechnology

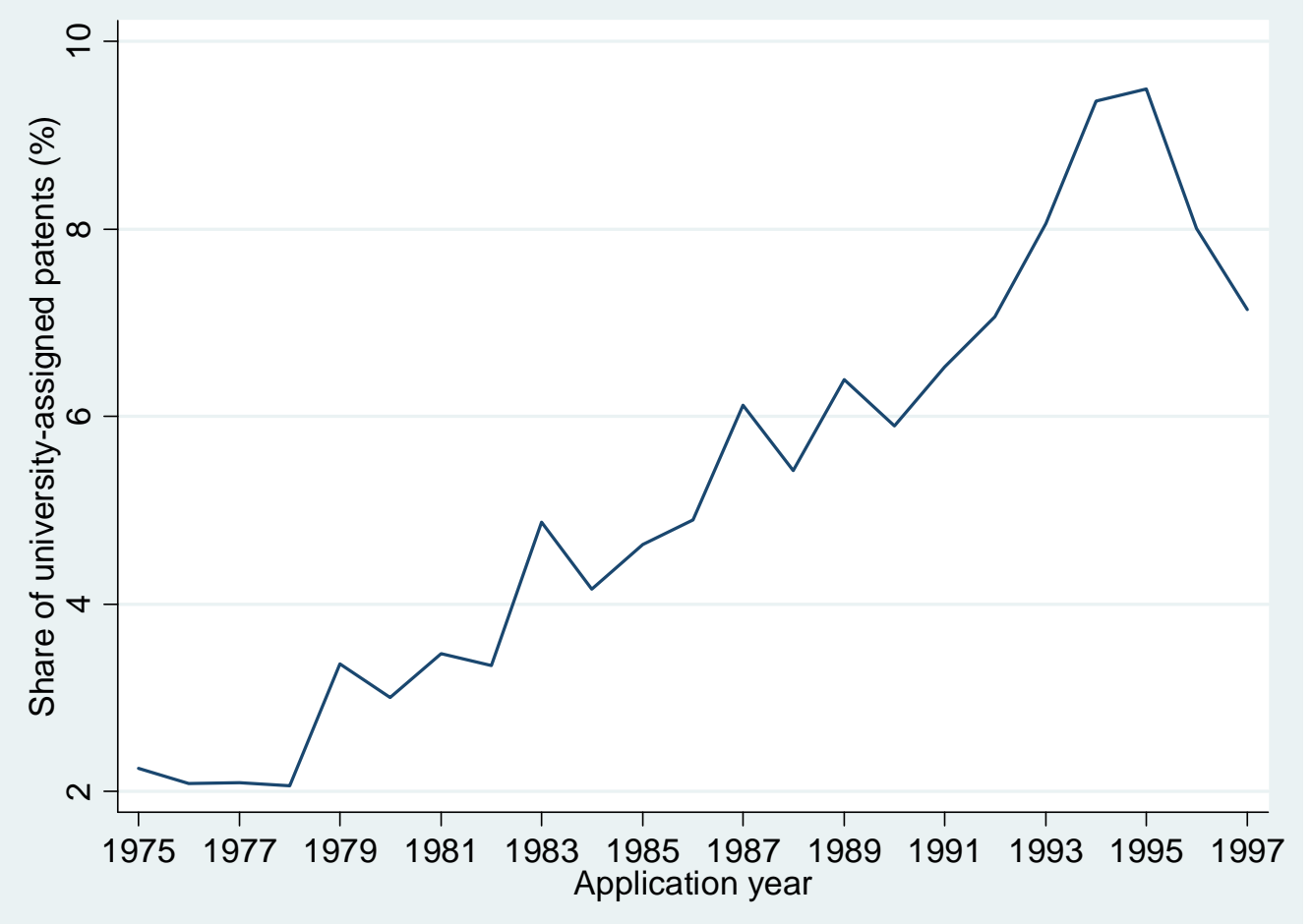


Figure 2 Industry Patents by Inventors with University Patent Experience in Nanotechnology

\section{A. Share of Patents}

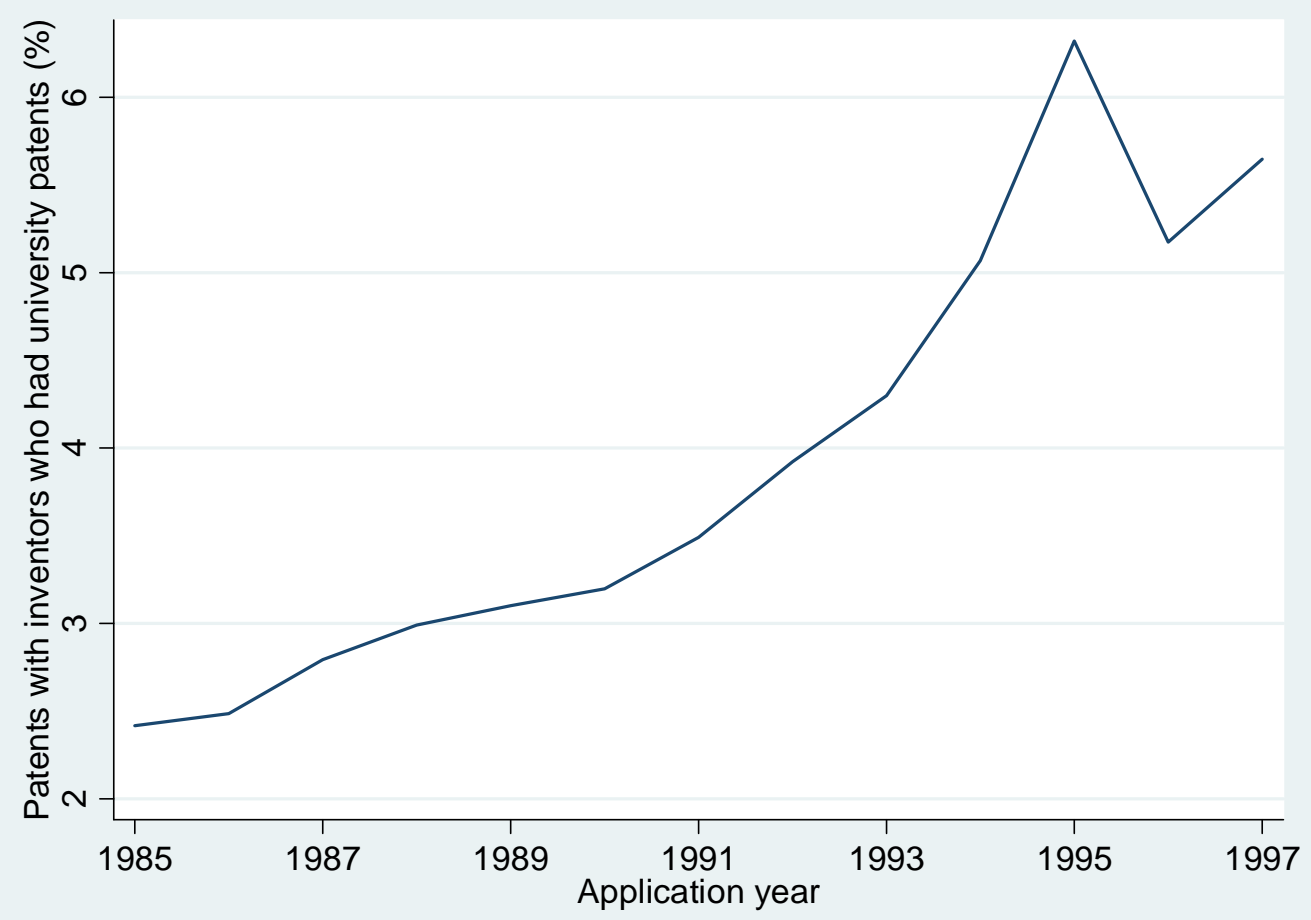

B. Share of Inventors

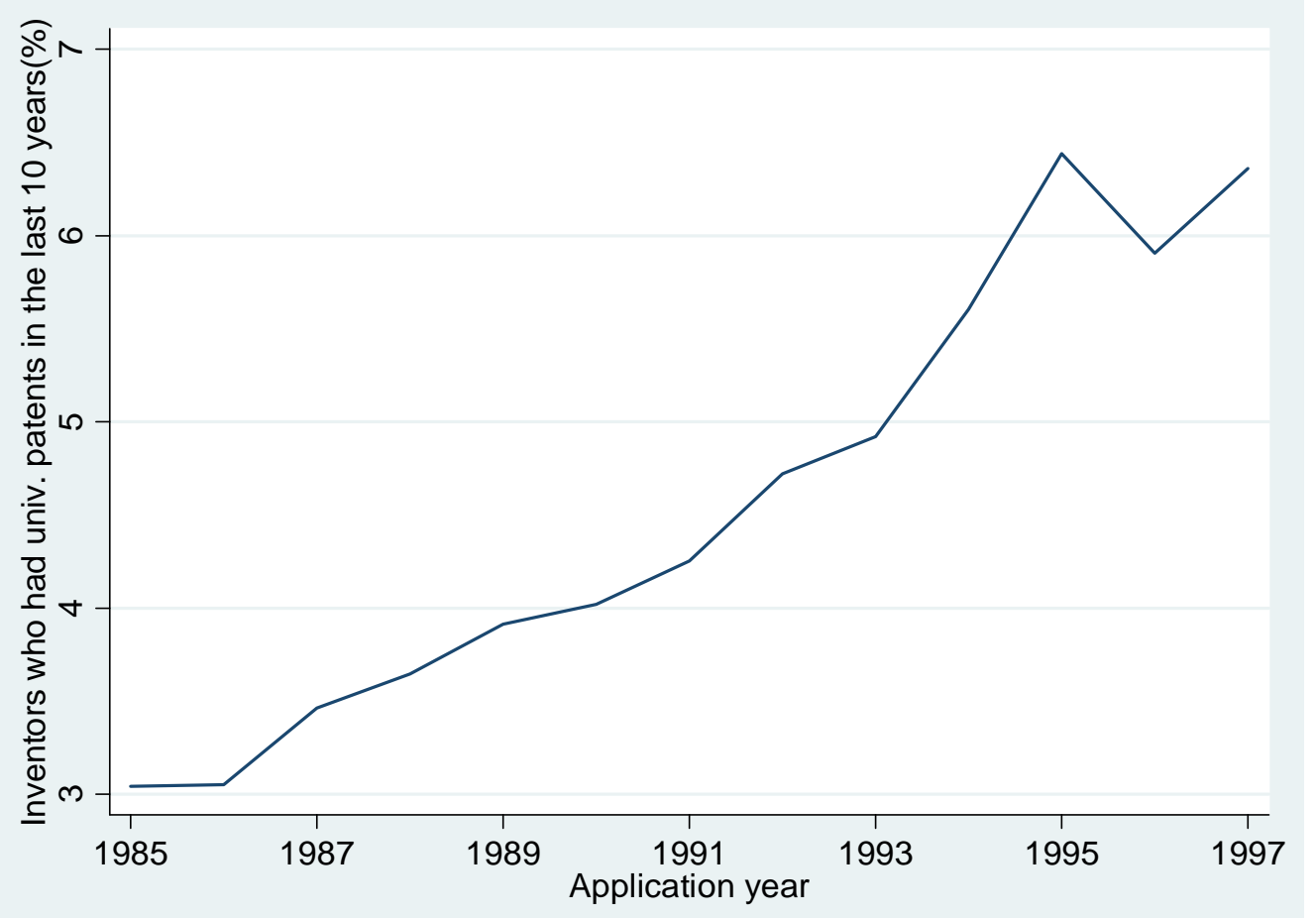


Figure 3 Average Citation Count for Nanotechnology Patents by Inventor Type

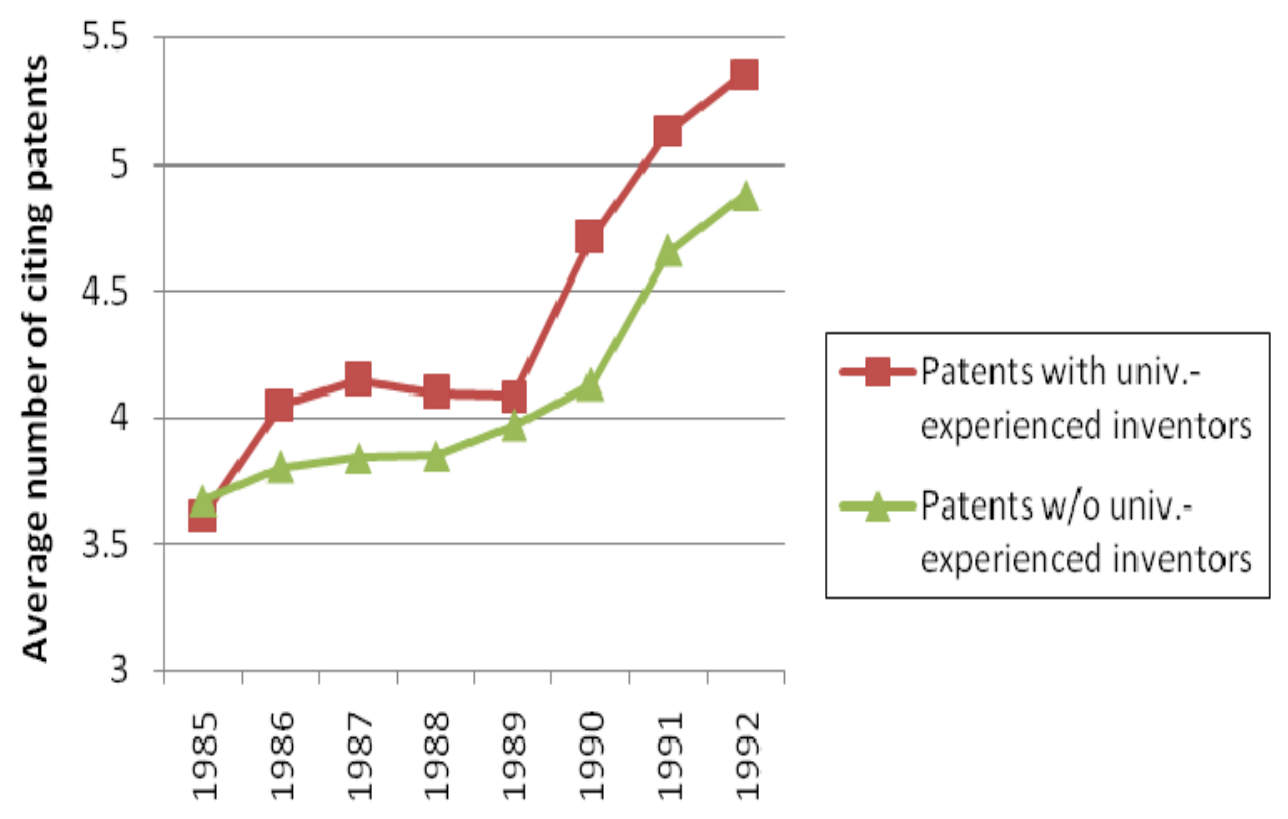

Application year

Figure 4 Patent Productivity of Inventors in Nanotechnology 


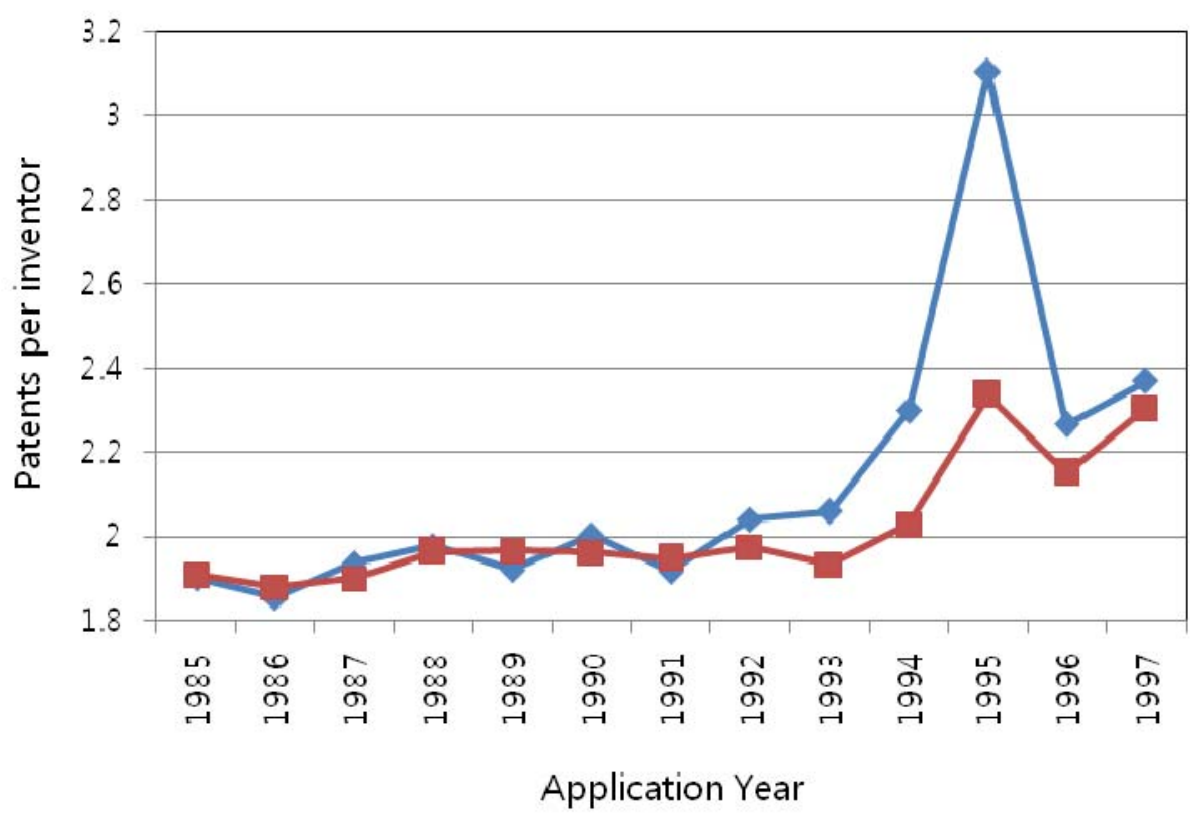

$\longrightarrow$ With univ. patent experience - w/o univ. patent experience 
Figure 5 Patent with Citations to University Patents in Nanotechnology

A. Share of Patents

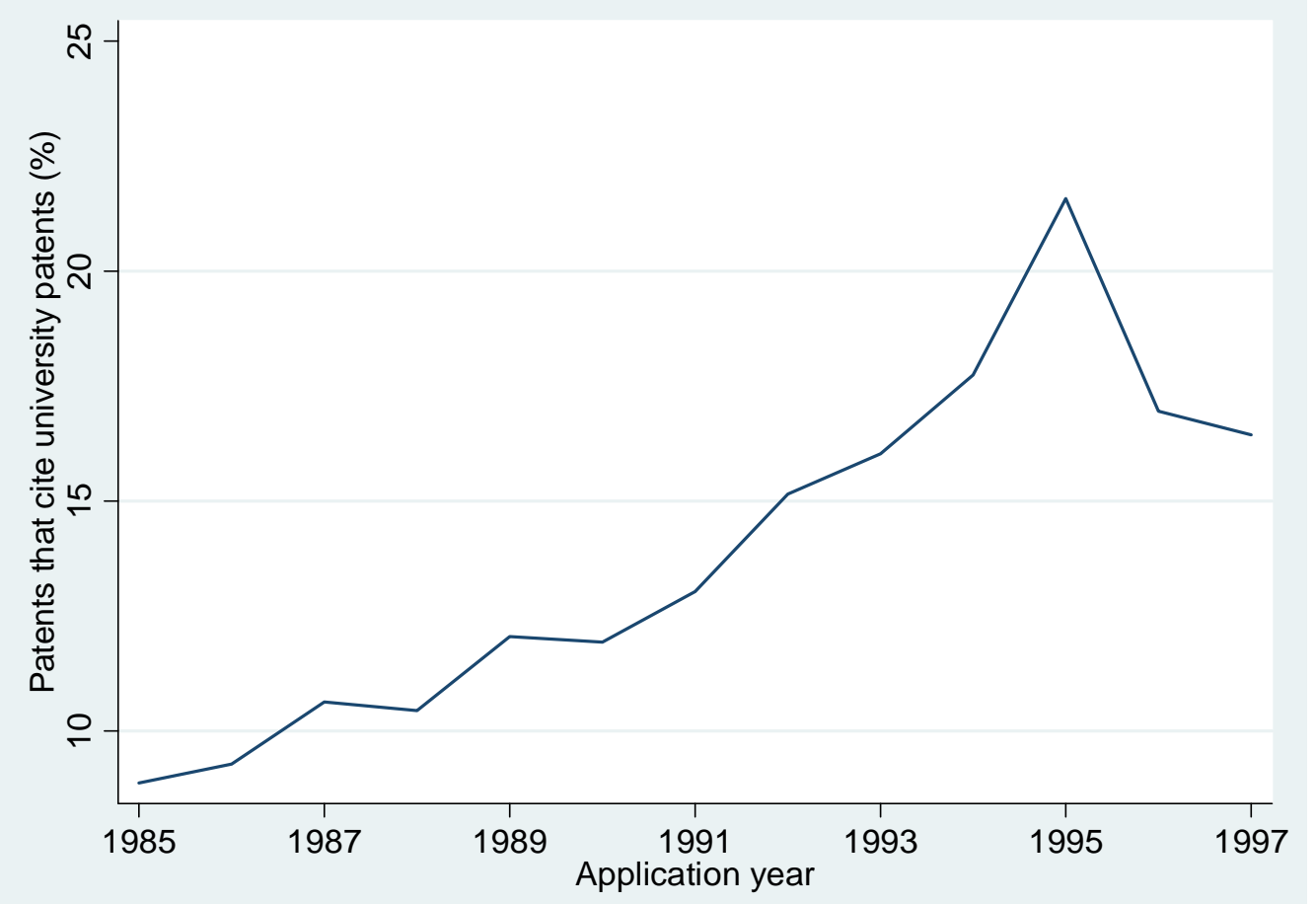

B. Share of Citations

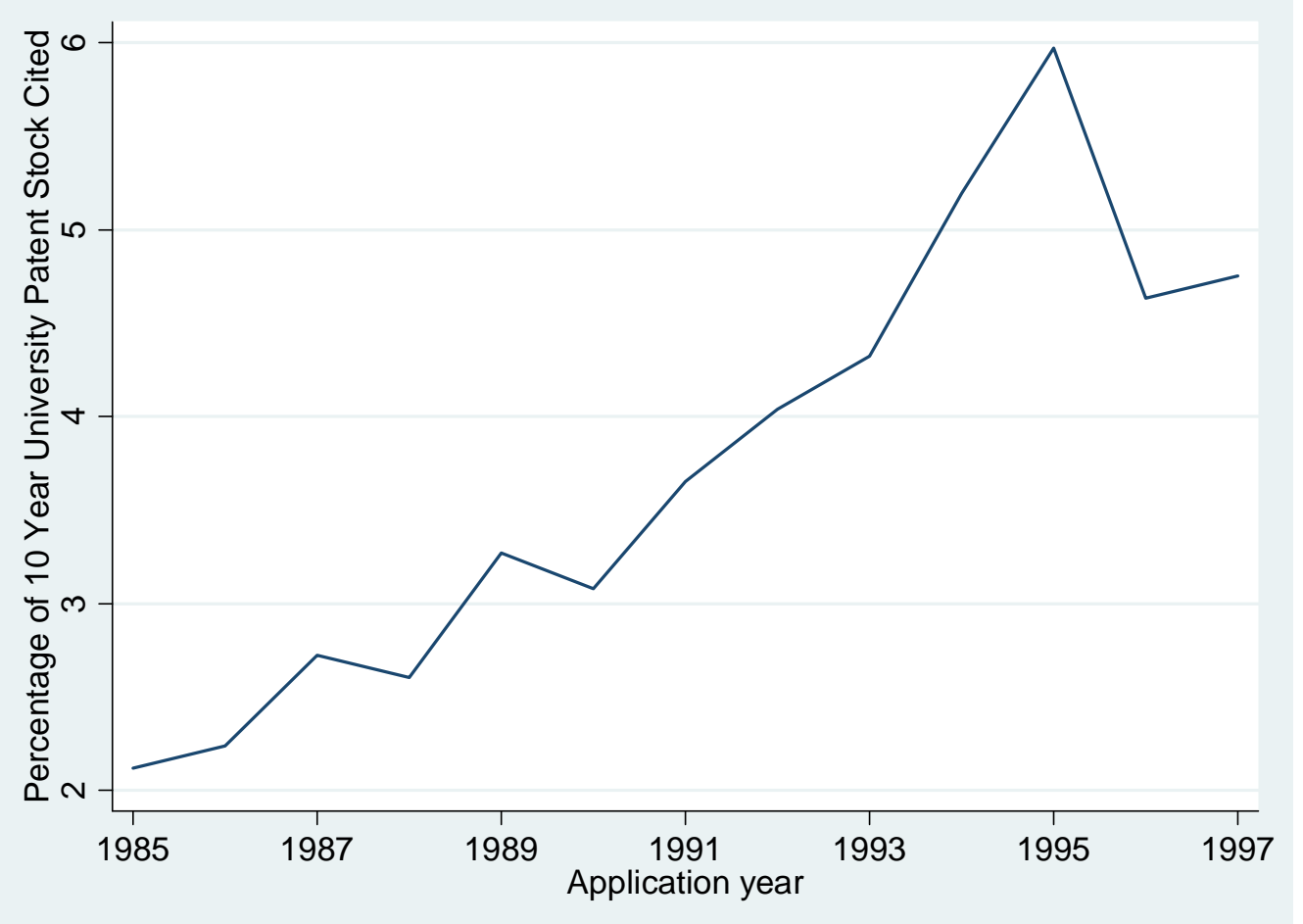


Figure 6 Share of Patents whose Inventors Self-Cite University Patents in Nanotechnology

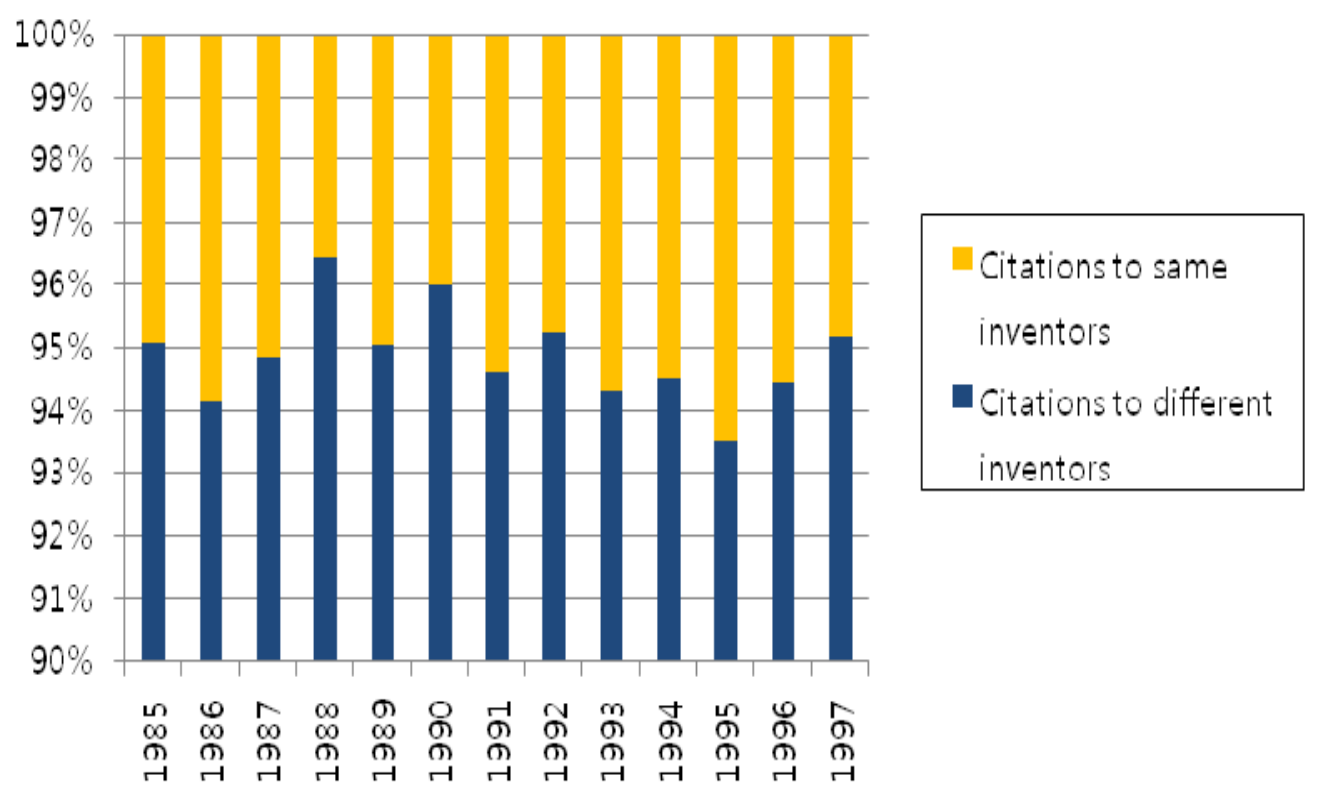

Application Year 
Table 1 Number of Patents in Nanotechnology

\begin{tabular}{ccc}
\hline \hline Application year & $\begin{array}{c}\text { Number of patents in } \\
\text { nanotechnology }\end{array}$ & $\begin{array}{c}\text { Number of university } \\
\text { patents in nanotechnology }\end{array}$ \\
\hline 1975 & 2004 & 45 \\
1976 & 2019 & 42 \\
1977 & 2054 & 43 \\
1978 & 2187 & 45 \\
1979 & 2203 & 74 \\
1980 & 2298 & 69 \\
1981 & 2276 & 79 \\
1982 & 2423 & 81 \\
1983 & 2506 & 122 \\
1984 & 2766 & 115 \\
1985 & 3215 & 149 \\
1986 & 3596 & 176 \\
1987 & 4234 & 259 \\
1988 & 5069 & 275 \\
1989 & 5633 & 360 \\
1990 & 6321 & 373 \\
1991 & 6938 & 453 \\
1992 & 8287 & 585 \\
1993 & 9580 & 772 \\
1994 & 11971 & 1121 \\
1995 & 16522 & 1568 \\
1996 & 14555 & 1165 \\
1997 & 17349 & 1238 \\
& & \\
\hline \hline Average annual growth rate & $10.78 \%$ & \\
& & \\
\hline
\end{tabular}

